Movimentos e Contramovimentos da democracia no Brasil: perspectivas e dilemas em contexto de instabilidades institucionais e reorganização política (Entrevista com James N. Green)

[Movements and countermovements of democracy in Brazil: perspectives and dilemmas in the context of institutional instability and political reorganization (Interview with James N. Green)]

\section{Liziane Guazina}

Universidade de Brasília

[University of Brasilia]

Fernanda Martinelli

Universidade de Brasília

[University of Brasilia]

João Guilherme Xavier da Silva

Universidade de Brasília

[University of Brasilia]



revista compolítica 2017, vol. 7(1) compolitica.org/revista ISSN: $2236-4781$ DOI: 10.21878/compolitica.2017.7.1.26o (2) Open Access Journal 


\title{
Movimentos e Contra-movimentos da democracia no Brasil: perspectivas e dilemas em contexto de instabilidades institucionais e reorganização política (Entrevista com James N. Green)
}

\author{
Liziane GUAZINA \\ Fernanda MARTINELLI \\ João Guilherme XAVIER DA SILVA
}

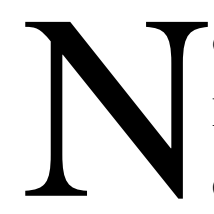

o dia 01 de abril de 2016, durante a assembleia geral do XIII Congresso da Brazilian Studies Association (BRASA), que aconteceu na Brown University, em Providence (Rhode Island - EUA), foi aprovada uma declaração sobre os riscos de retrocesso nas instituições democráticas do Brasil. A motivação para a apresentação dessa nota era a iminente possibilidade do afastamento da presidenta Dilma Rousseff de suas funções, sob a alegação de descumprimento da lei orçamentária por meio do que a imprensa brasileira chamou de "pedaladas fiscais". A despeito da insuficiência de argumentos sobre a ilegalidade dessa prática, o afastamento da presidenta pelo prazo máximo de 180 dias se confirmou em 12 de maio do mesmo ano, após o Senado decidir pela admissibilidade do processo de impeachment por 55 votos a favor e 22 contra.

Ao publicar essa declaração, a BRASA se tornou a primeira associação internacional a se posicionar publicamente contra as ameaças à democracia brasileira que ganharam força no primeiro semestre de 2016. O texto, disponível no site da Associação, afirma que "Ao invés de preservar a neutralidade política e o respeito ao devido processo legal, setores do Poder Judiciário, com o apoio dos interesses da grande mídia, tornaram-se protagonistas dos ataques ao Estado de Direito. Durante suas investigações, alguns funcionários públicos estão violando direitos fundamentais dos cidadãos, tais como presunção da inocência, garantia de Judiciário imparcial, sigilo da comunicação entre cliente e advogado, além do direito à privacidade".

A declaração foi aprovada por ampla maioria na assembleia. Ao longo do debate, a posição vencida em votação foi defendida por figuras notórias na BRASA, como seu ex- 
presidente e professor do King's College London, Anthony Pereira, que renunciou logo após a deliberação, antecipando o fim de seu mandato em um dia.

No dia seguinte a esses acontecimentos, o professor titular de História da América Latina na Brown University, diretor executivo e ex-presidente da Associação, James N. Green concedeu entrevista aos integrantes do Núcleo de Estudos sobre Mídia e Política (NEMPUnB) Liziane Guazina, Fernanda Martinelli e João Guilherme Xavier da Silva. Green respondeu a questões referentes à cobertura da mídia internacional sobre o processo de impeachment da presidenta, e traçou paralelos com o momento histórico que antecedeu o golpe civil-militar de 1964, além de analisar o posicionamento do governo americano e da comunidade acadêmica internacional.

Três meses depois, em julho de 2016, após uma rápida passagem de Green pela Universidade de Brasília, a entrevista foi retomada com foco na avaliação sobre a repercussão internacional dos primeiros 60 dias do governo interino, e nas mobilizações de movimentos sociais, pesquisadores e demais setores da sociedade civil em oposição a esse governo, especialmente às intervenções em políticas públicas inclusivas nas áreas de educação, cultura, direitos humanos e comunicação no horizonte político-eleitoral de 2018 .

\section{Parte I (abril/2016)}

Qual a sua avaliação sobre o cenário político brasileiro, a partir de sua experiência como estudioso do Brasil?

Talvez eu possa começar falando sobre qual é a leitura internacional da situação do Brasil [feita] pela mídia americana e internacional. Eu acho que há algumas reportagens muito boas, que estão conseguindo entender a complexidade da realidade e explicar isso para o leitor que não tem muito conhecimento do Brasil. Mas, infelizmente, noto várias mídias como, por exemplo, $\mathrm{BBC}$ (na rádio internacional "BBC World"), que há dois ou três dias está dizendo que Dilma seria impedida por causa da corrupção na Petrobras. Ou seja, 
fazem um link entre duas questões paralelas que talvez tenham uma relação no futuro, mas, por enquanto, não têm. Sabemos que, até agora, o impedimento é sobre as pedaladas, não sobre outra questão. Então, nesse sentido, eu acho que, na tentativa de transmitir uma complexidade em pequenas mensagens para o público internacional, falta muito na tradução. Chama muito a minha atenção a posição de The Economist apoiando a derrubada do governo. Eu acho que isso não cabe, especialmente porque todas essas revistas apoiaram a ditadura militar durante muitos anos sem críticas. Jamais The Economist pediu pela saída de Médici, de Geisel, de Costa e Silva. Então, eles não têm moral, do meu ponto de vista, hoje em dia para criticar o governo nesse sentido. Podem analisar que a situação está difícil, mas, fazer uma intervenção política, seria como a Rede Globo, que fez um ato crítico há alguns anos, reconhecendo que foi um erro apoiar a ditadura militar. E a Rede Globo está de novo fazendo uma intervenção política muito parcial que, para mim, ameaça a democracia; então, isso me irrita demais. Posso aceitar isso do New York Times, que já em 1970 denunciava a tortura no Brasil e chamava o governo americano a financiar o governo brasileiro, tendo assim apoiado essa prática. New York Times fez esse pronunciamento em 70, Washington Post também. Mas, The Economist, que nunca se posicionou sobre essas questões? Para mim, são interesses econômicos. Eles estão muito preocupados com a situação econômica muito precária nesse momento; estão preocupados com investimento, só isso, e não com a situação da democracia no Brasil, a defesa da democracia. Essa foi a minha primeira reação sobre a mídia internacional.

Sobre a complexidade nacional, eu tenho minhas opiniões, mas é minha análise individual. Acho que a questão fundamental nesse momento é de fortalecer as forças democráticas que estão preocupadas com a maneira com que o Judiciário está acelerado em sua capacidade de investigar e tentar criar uma situação. Eles querem criar uma situação... A situação já está criada: é o impedimento. Outra questão: como [Eduardo] Cunha tem moral de fazer qualquer coisa? Imaginem, ele dirigindo o impedimento da presidenta!? Acredito, pode ser que eu esteja errado... Em outro momento, podem dizer que ela se beneficiou de qualquer uma dessas manipulações de dinheiro, mas duvido disso profundamente. Acho que ela não se beneficiou em nada. Acho que ela tem uma moral classe média alta impecável, da formação da mãe dela, que era uma professora 
secundária ou primária, de uma cidade do interior de Minas Gerais. Não conheço a mãe dela, mas imagino uma senhora "dez", o pai dela também. Ainda, essa experiência que ela teve na clandestinidade; eu entrevistei várias pessoas, eu tenho certeza. Mas, Cunha? Que cara de pau dessa pessoa dirigindo o impedimento! Para mim, é revoltante.

Outra questão é que eles abriram uma "caixa de pandora", porque sabemos - todos os brasileiros sabem, é uma coisa assim já conhecida amplamente - que a corrupção começou há 500 anos, quando os portugueses chegaram e começaram a corromper os índios, todas as capitanias gerais [hereditárias], tudo isso baseado na troca de favores, interesses e porcentagens. Tudo isso, a colonização toda foi baseada nisso; sabemos que todos os partidos políticos estão envolvidos. Agora, os setores que estão contra o governo têm um grande problema: mesmo que eles argumentem "basta de investigações, a economia não merece, vamos congelar outras investigações, arquivá-las", eles estão criando uma situação em que as pessoas vão insistir por investigações sobre outros partidos, outras pessoas e personalidades, outros presidentes, e quem sabe o que vai acontecer com isso. Então, eu acho que eles 'abriram' uma situação, como em certo sentido os republicanos [nos EUA] — não fazendo uma analogia direta —, mas quando estes apoiaram o Tea Party, a elite do Partido Republicano, para poder fortalecer a sua base, criaram o [Donald] Trump. PSDB e PMDB podem criar uma situação que escape um pouco do seu controle, como aconteceu aqui.

Há o risco, em sua avaliação, de surgimento de um candidato outsider do sistema político, um "salvador da pátria”, como nós já tivemos na história brasileira?

Eu acho que salvador da pátria, eu vejo talvez Jânio Quadros. Não sei, porque ele sequer foi outsider, no sentido de que já havia sido vereador, prefeito, governador, era uma pessoa muito mercurial. Uma pessoa um pouco instável politicamente, mas já tinha uma tradição. Vargas não era um outsider quando ele chegou ao poder em 1930. Collor talvez fosse, mas ele também foi governador, então não era. Mas criou uma imagem de outsider [mais] do que realmente era. Ele estava totalmente embutido no sistema político de forma 
familiar, a família dele. Eu acho que é possível que haja um candidato a presidente muito fraco.

Qual foi o problema de João Goulart em 63, 64? Só tinha um terço do Congresso a seu favor. Qual foi o problema do PT quando assumiu o poder e por que o mensalão? Porque não tinha o controle do Congresso e eles compraram para ter controle, como compravam todo mundo antes, mas [daquela vez] foi descoberto e desmascarado, e o PT não sabia fazer o jogo como os outros fizeram. Foi justo que foram pegos e pagaram o preço por isso. Então, uma Marina ou um Bolsonaro, eu acho muito difícil. Outras figuras, como Moro, Barbosa, são pessoas que não vão consolidar esse apoio e, como o sistema parlamentar é totalmente baseado em troca de favores, ministros, de acesso aos aparelhos para cargo de confiança e troca de influência, favores por base de apoio político, caixa dois e tudo isso, ela, ele ou quem seja o próximo presidente, se for este ano, ano que vem ou 2018, vai entrar com um grande problema, porque não vai compor uma maioria.

E essas coalizões... Como o PMDB é tão oportunista... Quando ensino a história do Brasil, explico o Sarney. Quem foi o Sarney? Uma pessoa que apoiou durante vinte anos a ditadura. É como um rato que vai fugindo do barco quando está afundando. O PMDB, que era uma corrente autêntica, que lutou contra a ditadura, uma minoria do MDB, hoje é o partido mais corrupto no sentido mais básico. Eles se vendem para qualquer pessoa, a qualquer preço, para ficar no poder, sempre estão no poder. O PT está enfraquecido, vai ser derrubado e, em um momento ou outro, eles [do PMDB] irão para o PSDB. Mas eu acho que eles também estão muito mais fracos hoje em dia. $\mathrm{O}$ fato de que a corrupção está tão galopante, e com essas revelações da Odebrecht, não sei como vai ficar isso, mas eles vão sair fracos.

Então, essa presidenta ou presidente que vai ser eleito/a vai ser muito fraco/a e vai herdar também uma crise econômica... Se todo mundo está se queixando, essa crise econômica vai durar vários anos. PSDB, PMDB, o que eles vão fazer? Vão fazer o que Dilma está fazendo, mas mais intensivamente, porque o freio dela é que ela sempre tinha que pensar “qual vai ser a reação da CUT sobre essa medida?", "Vou perder minha base do PT se fizer essa medida?". PMDB e PSDB não têm que se preocupar com isso e têm uma classe 
média alta que vai ser feliz da vida de acabar com o Bolsa Família, com seus mitos sobre isso.

Eu estou careca de falar com as pessoas que pensam que aqueles com $\mathrm{R} \$ 200,00$ por mês não querem trabalhar porque têm R\$ 200,00 por mês. É uma pizza para uma família paulistana no fim de semana. Não sei, a inflação quanto está agora? É uma pizza, não é? Imagina que as pessoas não trabalham quando têm isso! É a salvação das famílias pobres do Brasil, essa bolsa. Então, vão acabar com isso, vão dizer que têm gastos, vão acabar com todos os programas sociais.

Eles insistem que nos últimos doze anos fizeram um novo pacto social que é impossível de dissolver. Não acho que isso é verdade; ele vai ser dissolvido. E vão inventar outras redes de solidariedade, colaborações comparativas, alguma coisa "para inglês ver", para aparentar que estão tentando resolver a desigualdade social. E eu digo tudo isso sendo muito crítico ao governo do PT e suas medidas insuficientes, sua incapacidade de enfrentar os setores conservadores do país, incapacidade política.

Eu me lembro muito bem do dia em que Lula foi eleito, eu estava em São Paulo. Fiz questão de ir para a Paulista e ficar mais perto dele para ver esse momento histórico. Queria reconhecer o momento histórico. E fiquei surpreendido com o discurso dele, que era um discurso muito personalista. "Eu, minha mãe, eu que fiz...", nada de dizer "eu estou aqui por causa de vinte anos, quinze anos de movimentos sociais, a partir de 77, 78, derrubando, criando uma nova cidadania. E para meu governo conseguir fazer tudo o que eu quero fazer, preciso de vocês ativamente envolvidos. Vamos fortalecer o PT, vamos fortalecer os movimentos sociais, vamos fortalecer tudo isso!". Ao contrário, "vamos enfraquecer, porque tem mais poder o PT no governo e não tem oposição ou crítica às pessoas". Então, o PT está pagando o preço por uma política errada durante muitos anos e pagando o preço por entrar no sistema de corrupção, entrar no sistema de troca de favores - que é normal - em vez de resistir. Ele perdeu totalmente a sua moral. O problema é que eu acho que algumas pessoas com uma falsa moralidade vão ocupar esse espaço. Pessoas que talvez tenham um tom religioso, que apelam à população brasileira, que tem uma religiosidade muito forte, pessoas que ficaram meio em cima do muro nessa 
situação. Mas, essas pessoas são fracas politicamente, com partidos minoritários e insignificantes, então acho que vai ser um movimento muito fraco e isso vai ser difícil para setores que estão derrubando o governo nesse momento.

É possível traçar um paralelo entre o clima de opinião pré-golpe de 1964 e clima de opinião que se vive hoje no Brasil? E como você avalia o papel dos meios de comunicação, em particular, nessa manutenção, criação ou fomento desse clima de opinião?

Foi a Tribuna da Imprensa... esqueci o nome do jornal que estava fazendo parte da campanha do Lacerda contra o governo em 64, publicando o bloco "Basta". Em seguida, eles perceberam que não era aquilo que eles imaginavam com isso. Bom, eu não vivi em 63-64, pesquisei bastante, mas eu nunca tentei fazer uma pesquisa sobre o feeling do momento. Então, a minha percepção é um pouco distante, mas eu acho que é mais polarizado hoje do que naquele momento. Eu falei com várias pessoas esta semana dizendo que viveram como jovens estudantes e que existia ainda certa cordialidade, ou um certo pacto social. "Ah, tudo bem, você é da esquerda, você é simpatizante do PC [Partido Comunista], você apoia esses novos grupos que estão surgindo, mas, tudo bem, somos todos brasileiros, vamos conversar". Aquela cordialidade que me chama muita atenção quando chego no Brasil, a maneira de tapar divergências com esse "ah, tudo bem, um abraço", eu gosto, mas é uma coisa, às vezes, muito falsa. E eu acho que isso não existe agora. Eu recebi e-mails super agressivos; uma falta de respeito total. Eu sou professor titular e tudo bem, não estou nem aí para isso, mas os brasileiros sabem que um professor titular americano tem que ser respeitado; então eu fico chocado com a maneira que eu estou sendo tratado por pessoas que são contra o abaixo-assinado que eu organizei. É uma grosseria, eu não consigo entender isso, porque, claramente, são pessoas que têm uma formação superior; imagino, pessoas que têm uma boa condição social, me tratar dessa maneira é chocante. Então, isso exige uma polarização que estava embutido na histeria anticomunismo em 63-64. Chamou-me muita atenção, quando a Dilma foi eleita, as pessoas no Leblon [dizendo]: "agora estamos em um país comunista, vamos 
para Miami”. Você sabe o que é Cuba? Você sabe o que foi a União Soviética? Não tem nada a ver, é uma analogia louca, de pessoas histéricas que perderam a noção da realidade. Você está onde dizendo isso? Leblon, Ipanema, ou sei lá o quê?

Eu acho que está mais polarizado, e acho que vai seguir muito polarizado, porque mesmo que Dilma não seja derrotada pelo impedimento, mesmo com muitas pessoas desmoralizadas pelo PT, por tudo o que aconteceu, há um ódio, uma raiva das esquerdas, dito amplamente, que eu acho que vai seguir e, espero que não, um golpe militar. Há uma certa democracia, mesmo limitada, para que as pessoas possam expressar essas ideias, esses sentimentos. Eu acho que as mídias sociais têm incentivado muito esse tratamento social chocante. Vocês devem saber melhor do que eu, porque eu realmente não gosto de frequentar muito, mas eu estou mais ou menos obrigado agora nesse momento pela situação - isso é preocupante para mim. A mídia como um todo manipulou em 64, com exceção do Última Hora e um ou outro jornal que sabemos, e está fazendo a mesma coisa hoje. É uma cobertura parcial, eles têm uma certa obrigação de tentar colocar supostamente dois lados da história, mas o exemplo clássico, fazem isso o tempo todo: você fala sobre Lula, pegam uma foto dele feio, gritando, com a cara, sabe, quando está falando com emoção? Ou Dilma. E quando é oposição à Dilma é uma pessoa bonita. $\mathrm{O}$ Aécio é muito bonitão, bem acomodado, de gravata. De todas as fotos de Lula, do arquivo, quando ele era grande amigo da alta burguesia, porque a economia estava crescendo, essas fotos dele de terno e gravata e bonito acabaram. Agora é o diabo, e a Veja é o [veículo] mais descarado nesse sentido... Eu nem falo sobre isso, porque para mim é baixo jornalismo, não tem nada a ver com a tentativa de Veja de ser uma Time Magazine, com certo estilo nobre, quer dizer, não tem nada de nobre na cobertura de Veja hoje em dia.

Como você percebe o interesse do governo americano no acompanhamento dessa situação no Brasil?

Você sabe que segunda-feira a subsecretária de relações com a América Latina vai estar nessa universidade? Ela estudou aqui. Ela volta e eu vou ter uma oportunidade de 
conversar com ela sobre isso. Eu não sei; eu não tenho percebido uma política claramente articulada, mas não sei ainda qual é a posição atual do governo americano, pois não tem havido declarações evidentes. Eu sei de uma coisa: um colega americano que mora no Brasil, professor universitário, recebeu uma mensagem da embaixada um dia antes das mobilizações do dia 18 - a favor do governo, contra o impedimento - advertindo os americanos para "tomar muito cuidado, que poderia ser muito perigoso o dia 18 nas ruas e, então, não deveriam sair". E ele perguntou: “mas vocês não fizeram isso para o dia 13 , por que estão avisando os americanos para tomar cuidado? Será que vocês estão tratando esses dois momentos de uma maneira parcial?”. Ele me mandou o e-mail que enviou para a embaixada, mas acho que não recebeu uma resposta, pois teria compartilhado [comigo].

Nesse sentido, eu posso imaginar que os funcionários do governo americano funcionários, não uma ordem internacional - , [que] moram nos Jardins, frequentam os restaurantes dos Jardins, seus filhos vão para a escola americana, uma série de situações culturais, imagino, onde eles estão nesse debate nesse momento. Eles iam achar chocante a miséria do país se não tivessem viajado para outros países antes de chegar ao Brasil — eu acho que a posição deles seria essa. Agora, [no caso da] política oficial, eu acho que Obama está olhando muito pouco para a América Latina. Talvez seja bom, talvez não. Eu acho que não há uma preocupação do governo americano nesse momento.

Você acha que a comunidade acadêmica internacional olha para essa situação com interesse, desinteresse, hostilidade?

Olha, quando iniciei esse abaixo-assinado, na verdade, eu estava em Nova York. Quando Lula foi eleito, entre o primeiro e segundo turno na primeira eleição, o Washington Times, que é um jornal da direita mesmo, financiado por um cara muito conservador, fez editoriais muito preocupantes sobre o Lula e tinha um clima de possível golpe. Governo Bush, não é? Mas, depois houve a Guerra do Iraque e o Bush se dedicou a essa guerra. Eu e outras pessoas fundamos o Brazil Strategy Network, que era uma tentativa de juntar os acadêmicos que estavam preocupados com o Brasil - brasilianistas - para responder à 
nova situação. Eu tinha certa preocupação com uma possibilidade de uma intervenção americana, mas não houve.

Quer dizer, o governo americano estava mais preocupado com o Iraque; Lula foi para a Casa Branca, abraçou o Bush, enfim. Mas essa iniciativa criou uma rede de pessoas e, a partir dela, conheci um grupo de brasileiros imigrantes. Foi maravilhoso, porque eram pessoas de classe média baixa, trabalhadores pegando qualquer serviço, de limpar casa, pintar casa, e eles tinham recriado Minas Gerais em Connecticut. Eles tinham recriado uma comunidade e me levaram para as cidades onde há concentração de brasileiros. Então, uma dessas pessoas que trabalhou muito comigo me chamou para um evento em Nova York e eu fui lá com minha filha, que tinha 6 anos. Isso me impactou muito e eu falei "não, eu tenho que responder". Nas vésperas do BRASA, alguém me pediu para fazer um abaixo-assinado e eu falei "não tenho nenhum momento para pensar nisso; eu quero, mas não posso, eu assino", mas eu senti muita necessidade. Então, eu e o Renan Quinalha escrevemos, baseados em um texto que a gente já tinha escrito, que estava mais ou menos circulando. Eu não achava o tom correto para um público americano, tinha que explicar bastantes questões, então fizemos o abaixo-assinado. Mas, eu estava com medo, porque, como diretor executivo da BRASA, as pessoas podiam misturar meu papel, podia influenciar isso. Então, eu mandei para cinquenta pessoas para conseguir as assinaturas iniciais. Todo mundo foi lindo demais: “Ai, que lindo o que você está fazendo, muito obrigado. Eu queria responder, mas não sabia como responder, que bom o que você está fazendo".

Com essas cinquenta, fizemos um abaixo-assinado pela internet e a intenção era [alcançar] pessoas fora do Brasil, mas, não sei se não ficou claro, muitos brasileiros queriam assinar e várias pessoas no Brasil incentivaram. Então, nós tivemos um problema de separar os brasileiros e as outras pessoas. Foi um trabalho muito difícil, a gente tinha que pedir as pessoas que indicassem sua filiação universitária, porque não cabia dentro do formulário do abaixo-assinado. Foi um trabalho 'de cão' fazer isso, procurar os nomes e ver de qual universidade [elas eram]. 
A reação foi espetacular em Berlim, Londres, na França, as pessoas começaram a circular. A gente já fechou o abaixo-assinado, mas estou recebendo dez novas assinaturas por dia. Então, a reação foi muito grande e também na assembleia geral da BRASA, ontem, ficou evidente que a grande maioria dos brasileiros acadêmicos sabe da situação, entende a situação. Pode ser totalmente criticando o PT, pode ser nunca mais votar no PT na vida, mas eles sabem o que implica a situação, e a grande maioria dos brasilianistas também, porque quem vai ao Brasil e fica comprometido com o país, é comprometido por uma questão intelectual, mas também emocional ou vivencial. De ter vivido situações no Brasil que tocaram seu coração e, por isso, resolveram dedicar sua vida profissional a esse país. E muitas dessas pessoas ficaram chocadas com a miséria, a desigualdade social, o racismo e tentam responder tanto nas suas pesquisas quanto nas suas aulas sobre o Brasil. Então, eles entenderam a tentativa, o objetivo dos governos de Lula e de Dilma, sejam quais forem os resultados, foi uma sensibilidade sobre a realidade, a necessidade de transformação social, [eles] são conscientizados sobre a realidade. Só uma ou outra pessoa que não gostou do texto, que não quis assinar, uma ou outra pessoa disse que não cabe à Associação posicionar-se nesse momento, mas o que eu sentia e estou sentindo pela reação é um grande apoio a essa iniciativa. E eu acho que isso vai seguir, porque a situação vai ser muito mais drástica nos próximos anos, e acho que vai haver uma sensibilidade dos brasilianistas de responderem a isso.

\section{Parte II (julho/2016)}

Qual o balanço que você faz da percepção internacional sobre os primeiros 60 dias do governo interino?

Um editorial do New York Times deixou muito claro que observadores internacionais têm a impressão que o governo de Temer contém políticos que possivelmente são corruptos e ele vai ter que tomar medidas muito drásticas para deixar claro que está decisivo em eliminar a corrupção. $\mathrm{O}$ fato de que três ministros que ele indicou renunciaram por causa 
de acusações de corrupção não ajuda a sua imagem, considerando que outros ainda estão no seu governo. Acho que há pouca confiança neste governo.

Após o desenrolar do processo de impeachment, qual sua avaliação sobre o papel do governo norte-americano nos acontecimentos políticos recentes no Brasil?

A minha avaliação é que o governo de Obama considera que o procedimento do impeachment é democrático, mas, formalmente ou publicamente não está fazendo uma intervenção visível. Acho que eles vão ficar contentes com um governo Temer, pois será mais pró-americano e aberto ao investimento norte-americano no país, incluindo a possibilidade de mais participação de capital daquele país no pré-sal. Tem que lembrar como os Clinton são muito amigos do FHC e a sua política econômica não diverge muito da orientação dos partidos de centro-direita - PMDB, PSD, PSDB, DEM etc.

Você se reuniu com a presidenta Dilma Rousseff em duas ocasiões no mês de junho de 2016, quando esteve em Brasília. Como avalia sua atuação política nesse momento de afastamento?

A pessoa que eu conheci, especialmente na entrevista sobre Herbert Daniel, de quem era grande amigo entre 1967 e 1969, é totalmente diferente das imagens projetadas na mídia. Ela foi tranquila, pensativa, generosa, calma, reflexiva e muito simpática. Não consigo entender por que Lula não está fazendo mais para apoiá-la neste processo, talvez porque ele tem interesses divergentes. Ela enfrenta um grande problema: a economia não anda bem e ela perdeu o apoio popular. Não acho que ela conseguiu oferecer um caminho alternativo para poder reverter os problemas que o país enfrenta neste momento, e ainda não tem uma maioria na Câmara para poder aprovar qualquer medida. Mas, se o impeachment for aprovado no Senado, acho que ela vai sair digna e ser lembrada como uma presidenta honesta e patriótica. 
Existe uma grande expectativa no Brasil em torno da reorganização das forças partidárias com o horizonte político-eleitoral de 2018. Independentemente do resultado do processo de impeachment, em sua avaliação, quais serão os desdobramentos da crise política para os movimentos sociais populares e os grupos de esquerda?

As esquerdas e os movimentos sociais têm vários grandes desafios. O primeiro é fazer autocríticas profundas sobre a questão de corrupção no poder. Ainda não vejo muita disponibilidade neste sentido, é mais um argumento de que "todos fizeram, mas só o PT foi acusado". O segundo grande desafio é de debater e determinar quais são os princípios que as esquerdas e os movimentos sociais acham que não são negociáveis. No passado, a pressão de negociar alianças para ter uma maioria levou Lula e Dilma a fazer acordos com partidos e correntes dentro de partidos corruptos e contra princípios básicos, por exemplo, plenos direitos para pessoas LGBTT, direito ao aborto, defesa de conquistas trabalhistas. As esquerdas têm que decidir o que não é negociável. Têm que acordar com um programa progressista e defendê-lo. Precisam governar com uma honestidade e transparência que nunca houve no Brasil. Vão ter que reconquistar a confiança do povo, das classes médias e setores discriminados, pois perderam este apoio.

Do ponto de vista dos direitos humanos e da cidadania, qual cenário você prevê para os próximos anos no Brasil?

Diferentemente do governo neoliberal de FHC, um possível governo Temer, e depois em 2018 um possível governo do centro-direita, seria baseado em um programa economicamente e socialmente conservador, com uma base religiosa e fanática que vai querer implantar um regime baseado em ideias reacionárias, fundamentadas na Bíblia e em visões retrógradas. Ou seja, acho que as conquistas dos últimos anos dos movimentos LGBTT, feminista e negro vão ser parcialmente desmontadas junto com os programas sociais dos governos Lula-Dilma. Infelizmente, faz parte de uma onda conservadora mundial. Os governos do centro-direita não vão respeitar os direitos humanos. 


\section{Os autores}

Liziane Guazina é professora do Programa de Pós-Graduação em Comunicação da FAC-UnB, coordenadora do NEMP (Núcleo de Estudos sobre Mídia e Política) e líder do Grupo de Pesquisa Cultura, Mídia e Política (CNPq). liziane.g@uol.com.br

Fernanda Martinelli é professora do programa de Pós-Graduação em Comunicação da FACUnB, pesquisadora do NEMP (Núcleo de Estudos sobre Mídia e Política), líder do Grupo de Pesquisa Cultura, Mídia e Política (CNPq) e pesquisadora associada da CIEC (Coordenação Interdisciplinar de Estudos Contemporâneos (CNPq/Eco-UFRJ). nandamartineli@yahoo.com.br

João Guilherme Xavier da Silva é especialista em Políticas Públicas e Gestão Governamental. Doutorando no Programa de Pós-Graduação em Direito, Estado e Constituição da FD-UnB, e pesquisador do NEMP (Núcleo de Estudos sobre Mídia e Política). ig.granja@gmail.com 